\title{
In reply: Potential risks associated with intensive care unit aerosol isolation hood use
}

\author{
Samuel J. Smith, MD, MPH · Jingping Wang, MD, PhD
}

Received: 23 July 2020/Accepted: 23 July 2020/Published online: 3 August 2020

(c) Canadian Anesthesiologists' Society 2020

To the Editor,

We appreciate the response from Drs Basaran and Yilbas ${ }^{1}$ regarding our recent publication "Intensive care unit isolation hood decreases risk of aerosolization during noninvasive ventilation with COVID-19". ${ }^{2}$ The concerns they raise are understandable and have been addressed by our team and documented in our recent submission to the Food and Drug Administration (FDA) for Emergency Authorization Use (EUA) on the same series hood, the latest model employed being the Apollo Isolation Hood (AIH).

In terms of the consideration of infection control, the plastic hood is not disassembled at end of use; instead, the drape remains facing into the hood to contain the contaminated interior surfaces and is entirely enclosed in a disposal bag for discarding in its assembled form. Our institutional infection control team approved this approach and we have successfully implemented this clean disposal technique. We had used it as an "intubating barrier device" and this experience allowed us to use it on patients for essential airway interventions during the pandemic.

In addressing the concerns of emergency airway access to patient, this AIH was specifically designed to allow rapid removal ( $<$ five seconds). It has been used in a multitude of clinical situations in COVID-19 patients at Massachusetts General Hospital in Boston, including airway intubations, esophagogastroduodenoscopy, extubations from ventilator

S. J. Smith, MD, MPH · J. Wang, MD, PhD ( $ه)$

Department of Anesthesia, Critical Care and Pain Medicine,

Massachusetts General Hospital, Boston, MA, USA

e-mail: jwang23@mgh.harvard.edu to continuous positive airway pressure therapy, and highflow nasal cannula therapy in awake patients. Of note, rapid removal was done easily and safely by the healthcare workers $(\mathrm{HCW})$ in a patient in whom they encountered a remarkably difficult airway. It has also been employed successfully without notable safety concerns for intubations that were considered challenging in other patients. We have compiled these data for the FDA EUA.

Going forward, we recommend caution when using barrier devices during airway procedures and encourage open source access to hood designs to allow collaborative refinement of these devices through judicious use in patients and further laboratory testing. We are in the process of such additional testing to develop the urgently needed improvements in source control, as the only viable alternatives (i.e., N95, powered respirators, etc.) are fraught with their own problems, including communication impairment during critical situations, doffing risks, and HCW stress. ${ }^{3-5}$ They also contribute a little to the future of true mitigation through source control in reducing infectious transmission.

Disclosures None.

Funding statement None.

Editorial responsibility This submission was handled by Dr. Hilary P. Grocott, Editor-in-Chief, Canadian Journal of Anesthesia.

\section{References}

1. Basaran B, Yilbas AA. Potential risks associated with intensive care unit aerosol hood use. Can J Anesth 2020; DOI: https://doi. org/10.1007/s12630-020-01780-8. 
2. Shaw KM, Lang AL, Lozano R, Szabo M, Smith $S$, Wang $J$. Intensive care unit isolation hood decreases risk of aerosolization during noninvasive ventilation with COVID-19. Can J Anesth 2020; DOI: https://doi.org/10.1007/s12630-020-01721-5.

3. Shehchang H, Yuditsky T, Schulz KA, Dorsey H, Deshmukh AR, Sharra J. Evaluation of Human Performance While Wearing Respirators. December 2009 Technical Report, U.S. Department of Transportation; Federal Aviation Administration. Available from URL: $\quad$ https://hf.tc.faa.gov/publications/2009-evaluation-ofhuman-performance/full_text.pdf (accessed July 2020).
4. Radonovich LJ Jr, Cheng J, Shenal BV, Hodgson M, Bender BS. Respirator tolerance in health care workers. JAMA 2009; 301: 368.

5. Chughtai AA, Chen X, Macintryre CR. Risk of self-contamination during doffing of personal protective equipment. Am J Infect Control 2018; DOI: https://doi.org/10.1016/j.ajic.2018.06.003.

Publisher's Note Springer Nature remains neutral with regard to jurisdictional claims in published maps and institutional affiliations. 